\title{
Modification of the Pet-Membrane/Solution Interface: Effect on Electrical Parameters
}

\author{
J. Benavente, R. de Lara* \\ Grupo de Caracterización Electrocinética y de Transporte en Membranas e Interfases \\ Departamento de Física Aplicada I. Facultad de Ciencias. Universidad de Málaga. \\ E-29071 Málaga (Spain)
}

\begin{abstract}
Electrochemical characterization of a symmetric track-etched polyethylenthereftalate (PET) membrane in contact with $\mathrm{KCl}$ solutions at different concentrations was carried out by measuring impedance spectroscopy (IS) and membrane potential (MP), which allow the estimation of membrane electrical resistance and ion transport numbers, respectively. IS measurements permit us the characterization of membranes in "working conditions" (in contact with electrolyte solutions) and the determination of electrical parameters for the membrane and the membrane/solution interface (resistance, capacitance and Warburg impedance) by analyzing the impedance plots and using equivalent circuits as models. The non-reproducibility of membrane potential values for two series of measurements and the asymmetry of the impedance curves show the modification of the membrane/aqueous solution interface. This point was confirmed by the time evolution of the membrane system electrical resistance and the increase of nitrogen content obtained from X-ray photoelectron spectroscopy (XPS) analysis for dry and PET samples maintained in water for different periods of time, and the results indicate an increase in nitrogen content, which is attributed to bacterial presence on the membrane surfaces. These results seem to indicate modification of the PETmembrane/solution interface due to fouling and the possibility of its determination by electrical measurements.
\end{abstract}

Keywords: PET-membrane; impedance spectroscopy, membrane potential, XPS.

\section{Introduction}

Membrane fouling due to the adsorption/deposition of particles or bacterial contamination during ultrafiltration, which strongly reduces the volume flow and

\footnotetext{
* Corresponding author. E-mail address: J_Benavente@uma.es
} 
consequently the efficiency of the process, is one of the main problems for the application of membrane technology to food processing and pharmaceutical industries (1-2). Membrane fouling mechanisms are related to (3): i) formation of a gel/cake layer on the membrane surface, which causes the modification of the membrane/solution interface; ii) pore constriction and iii) pore plugging; these fouling mechanisms depend on both the membrane pore size and membrane-solute interactions. Hydrodynamic and streaming/zeta potential measurements are commonly carried out to estimate membrane fouling (4-7), but other kind of electrical measurements such as membrane potential (MP) and impedance spectroscopy (IS) can also be used to detect it (8). Particularly, IS results can indicate changes in the membrane/solution interface, which can be corroborated by other surface characterization techniques such as scanning electron microscopy (SEM), atomic force microscopy (AFM) and X-ray photoelectron spectroscopy (XPS) (9-11).

This work studies characteristic membrane electrical parameters (ion transport numbers and electrical resistance) determined from membrane potential and impedance spectroscopy measurements for an experimental ultrafiltration polyethylentereftalate (PET) membrane in contact with aqueous $\mathrm{KCl}$ solutions at different concentrations. Interfacial effects obtained from IS measurements are correlated with the increase of the nitrogen atomic concentration on the surface of wet membrane samples determined by XPS.

\section{Experimental}

\section{Membranes and solutions}

A symmetric experimental track-etched polyethylentereftalate (PET) membrane for ultrafiltration process, kindly supplied by Dr. A. Nechaev (Laboratory of Nuclear Filters, Russian Academy of Science, Moscow), was studied. Characteristic membrane geometrical parameters given by the supplier are: average pore radii, $<\mathrm{r}_{\mathrm{p}}>=(70 \pm 5) \AA$, thickness, $\Delta \mathrm{x}=10 \mu \mathrm{m}$, pore density, $\mathrm{N}=3 \times 10^{13} \mathrm{~m}^{-2}$.

Electrochemical measurements were carried out with the membrane in contact with aqueous $\mathrm{KCl}$ solutions at different concentrations, at room temperature $\mathrm{t}=(25.0 \pm$ $0.4){ }^{\circ} \mathrm{C}$ and standard $\mathrm{pH}(5.9 \pm 0.4)$. Before use, the membranes were immersed for at least $18 \mathrm{~h}$ in a solution of the appropriate concentration.

\section{Membrane potential and impedance spectroscopy measurements}

Measurements were carried out in a dead-end test cell consisting basically of two glass half-cells where the membrane was tightly clamped by using silicone rubber rings. In order to minimise concentration-polarisation at the membrane surfaces, a magnetic stirrer with a stirring rate of 525 r.p.m. was placed at the bottom of each half-cell. Two reversible $\mathrm{Ag} / \mathrm{AgCl}$ electrodes were used for both membrane potential and impedance spectroscopy measurements.

The electromotive force $(\Delta \mathrm{E})$ between both sides of a membrane caused by a concentration gradient was measured by connecting the two reversible electrodes to a digital voltmeter (Yokohama 7552, $1 \mathrm{G} \Omega$ input resistance). Measurements 
were carried out by keeping the concentration of the solution at one side of the membrane constant, $\mathrm{c}_{1}=$ const $=0.01 \mathrm{M}$, and gradually changing the concentration of the solution at the other side, $\mathrm{c}_{2}$, from $10^{-3} \mathrm{M}$ to $0.5 \mathrm{M}$. Membrane potential, $\Delta \Phi_{\mathrm{m}}$, was obtained by subtracting the electrode potential, $\Delta \Phi_{\mathrm{e}}=-\left(\mathrm{RT} / \mathrm{z}_{-} \mathrm{F}\right) \ln \left(\mathrm{a}_{1} / \mathrm{a}_{2}\right)$, from the corresponding $\Delta \mathrm{E}$ measured value. Two series of measurements were carried out under the same experimental conditions, the first series $\left(\Delta \Phi_{\mathrm{m}}{ }^{\mathrm{A}}\right)$ was measured with a non-used membrane (after its equilibration overnight with the constant concentration solution), and the second series was obtained with the same membrane and equilibration condition, but the membrane was maintained in contact with aqueous $\mathrm{KCl}$ solutions for 10 days $\left(\Delta \Phi_{\mathrm{m}}{ }^{\mathrm{B}}\right)$.

Impedance Spectroscopy (IS) measurements were carried out by using an Impedance Analyzer (Solartron 1260) controlled by a computer. The experimental data were corrected by software as well as the influence of connecting cables and other parasite capacitances. The measurements were carried out using 100 different frequencies in the range $10 \mathrm{~Hz}-107 \mathrm{~Hz}$ at a maximum voltage of $0.01 \mathrm{~V}$, the solutions at both sides of the membrane having the same concentration. For time evolution of the membrane system electrical resistance a Wayne Kerr A.C. bridge at a constant frequency ( $\mathrm{f}=1 \mathrm{k} \mathrm{Hz}$ ) was used.

\section{Chemical surface characterisation of membranes}

Surface chemical characterisation was carried out by X-ray photoelectron spectroscopy (XPS) using a Physical Electronics PHI 5700 spectrometer with a non monochromatic $\mathrm{Mg} \mathrm{K} \alpha$ radiation $(300 \mathrm{~W}, 15 \mathrm{kV}, 1253.6 \mathrm{eV})$ as excitation source. High-resolution spectra were recorded at $45^{\circ}$ take-off-angle by a concentric hemispherical analyser operating in the constant pass energy mode at $29.35 \mathrm{eV}$, using a $720 \mu \mathrm{m}$ diameter analysis area. Charge referencing was done against aliphatic/aromatic carbon (C 1s $285.0 \mathrm{eV})(12)$. Survey spectra in the range $0-1200 \mathrm{eV}$ were also recorded at $187.85 \mathrm{eV}$ of pass energy. Software package used for acquisition and data analysis, as well as the procedure used for determining atomic concentration percentages (A.C.) of the membrane surface elements are described in detail elsewhere (13).

\section{Results and discussion}

Membrane electrochemical characterization was carried out by measuring membrane potential or electrical potential difference at both sides of a membrane separating two solutions of the same electrolyte but different concentrations. According to the Teorell-Meyer-Sievers or TMS theory (14-15), the membrane potential can be considered as the sum of two Donnan potentials (one at each membrane/solution interface) plus a diffusion potential in the membrane, i.e.: $\Delta \Phi_{\mathrm{m}}=\Delta \varnothing \operatorname{Don}(\mathrm{I})^{+} \Delta \boldsymbol{d i f}^{+} \Delta \varnothing \operatorname{Don}(\mathrm{II})$. Membrane potential can be expressed by (16): 


$$
\begin{aligned}
\Delta \Phi_{\mathrm{m}}=(\mathrm{RT} / \mathrm{wzF})\{ & \ln \left(\mathrm{c}_{1}\left[\left(1+4 \mathrm{y}_{1}\right)^{1 / 2}+1\right] / \mathrm{c}_{2}\left[\left(1+4 \mathrm{y}_{2}\right)^{1 / 2}+1\right]+\right. \\
& +\mathrm{w} \mathrm{U} \ln \left\{\left[\left(1+4 \mathrm{y}_{1}\right)^{1 / 2}-\mathrm{wU}\right] /\left[\left(1+4 \mathrm{y}_{2}\right)^{1 / 2}-\mathrm{wU}\right]\right\}
\end{aligned}
$$

where $\mathrm{X}_{\mathrm{f}}$ is the membrane fixed charge concentration, $\mathrm{w}=-1$ or +1 for negatively or positively charged membranes, respectively, while $t_{i}$ is the transport number of the ion $i$ in the membrane, $\mathrm{z}_{\mathrm{i}}$ its valence $(\mathrm{i}=+$ for cation, for anion) and $\mathrm{yj}_{\mathrm{j}}=\mathrm{Zj}_{\mathrm{j}} \mathrm{cj}_{\mathrm{j}} / \mathrm{wX}_{\mathrm{f}}$, where $\mathrm{k}_{\mathrm{S}}$ is the salt partition coefficient in the membrane; $\mathrm{R}$ and $\mathrm{F}$ are the gas and Faraday constants and $\mathrm{T}$ is the thermodynamic temperature of the system. $U$ is a parameter related to ion transport numbers in the membrane: $U=\left[\left(t_{-} /\left|z_{-}\right|\right)-\left(t_{+} /\left|z_{+}\right|\right)\right]$, where $t_{i}$ represents the amount of current transported for one ion with respect to the total current crossing the membrane, $\mathrm{t}_{\mathrm{i}}=\mathrm{I}_{\mathrm{i}} / \mathrm{IT}$, that is, $\mathrm{t}_{+}+\mathrm{t}=1$. If the Donnan potential can be neglected, membrane potential can be considered as a diffusion potential (16):

$$
\Delta \Phi_{\mathrm{m}} \approx \Delta \emptyset_{\mathrm{dif}}=(\mathrm{RT} / \mathrm{F})\left[\left(\mathrm{t}_{-} / \mathrm{z}_{-} \mid\right)-\left(\mathrm{t}_{+} / \mathrm{z}_{+} \mid\right)\right] \ln \left(\mathrm{a}_{1} / \mathrm{a}_{2}\right)
$$

Fig. 1 shows the membrane potential $\left(\Delta \Phi_{\mathrm{m}} \mathrm{A}\right.$ and $\left.\Delta \Phi_{\mathrm{m}} \mathrm{B}\right)$ versus logarithm of the solution activity ratio, $\ln \left(\mathrm{a}_{1} / \mathrm{a}_{2}\right)$ or $\ln \left(\mathrm{a}_{\mathrm{v}} / \mathrm{a}_{\mathrm{c}}\right)$ according to the identification given in Section 2.2, as well as the theoretical membrane potential for an ideal cation-exchange (c-ex) membrane (no anion transport exists, then $\mathrm{t}_{+} \mathrm{c}$-ex $=1$ ). As can be observed, at low concentrations $\Delta \Phi_{\mathrm{m}} \mathrm{A}$ and $\Delta \Phi_{\mathrm{m}} \mathrm{B}$ values hardly differ one from each other, and from those corresponding to the ideal exchange membrane, but at high concentrations $(c>0.05 \mathrm{M})$ significant differences were obtained. These results seem to indicate a Donnan exclusion of the counter-ion (anion) when the solution concentration is lower than the membrane fixed charge concentration, but its effect can be neglected at high solution concentration when the diffusion potential dominates the transport of ions across the membrane, then: $\Delta \varnothing_{\text {dif }} \approx \Delta \varnothing_{\mathrm{m}}$, and the determination of the apparent cation transport number in the membrane can be obtained from the slope the straight line at high concentrations according to Eq. (2).

The following average values for cationic transport number were obtained: $\left.<\mathrm{t}_{+}(\mathrm{A})\right\rangle=(0.78 \pm 0.04)$ and $\left\langle\mathrm{t}_{+}(\mathrm{B})\right\rangle=(0.65 \pm 0.03)$, which indicates the electronegative character of the PET membrane $\left(t_{+}(\right.$memb $)>t_{+}$(solution) $\sim$ 0.49); on the other hand, although both series of measurements present the same tendency, the significant differences obtained for $\Delta \varnothing_{\mathrm{m}}$ and $\left\langle\mathrm{t}_{+}>\right.$values with dry (sample $\mathrm{A}$ ) and 10 days $\mathrm{KCl}$-aqueous solution equilibrated (sample $\mathrm{B}$ ) membranes seem to indicate modifications in the membrane pore or in the membrane/solution interface associated to membrane fouling (bio-fouling). 


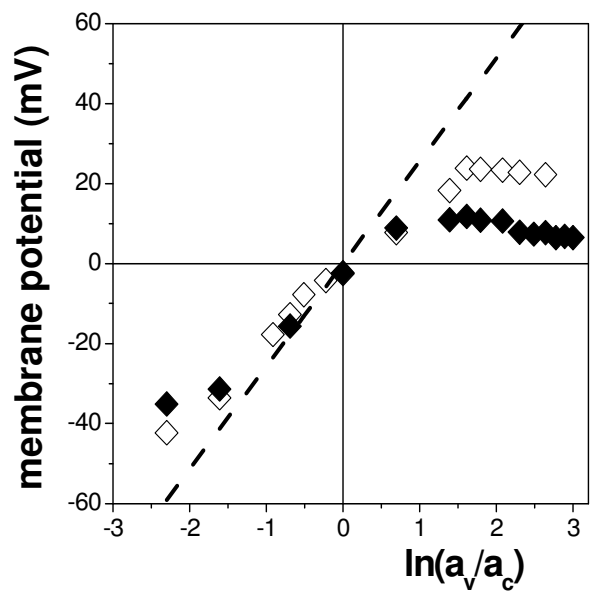

Figure 1. Membrane potential versus $\ln \left(a_{1} / a_{2}\right)$ for two series of measurements with PET membrane and $\mathrm{KCl}$ solutions. $(\diamond)$ first series (sample A), $(\diamond)$ second series (sample B), (- - ) cation-exchange membrane.
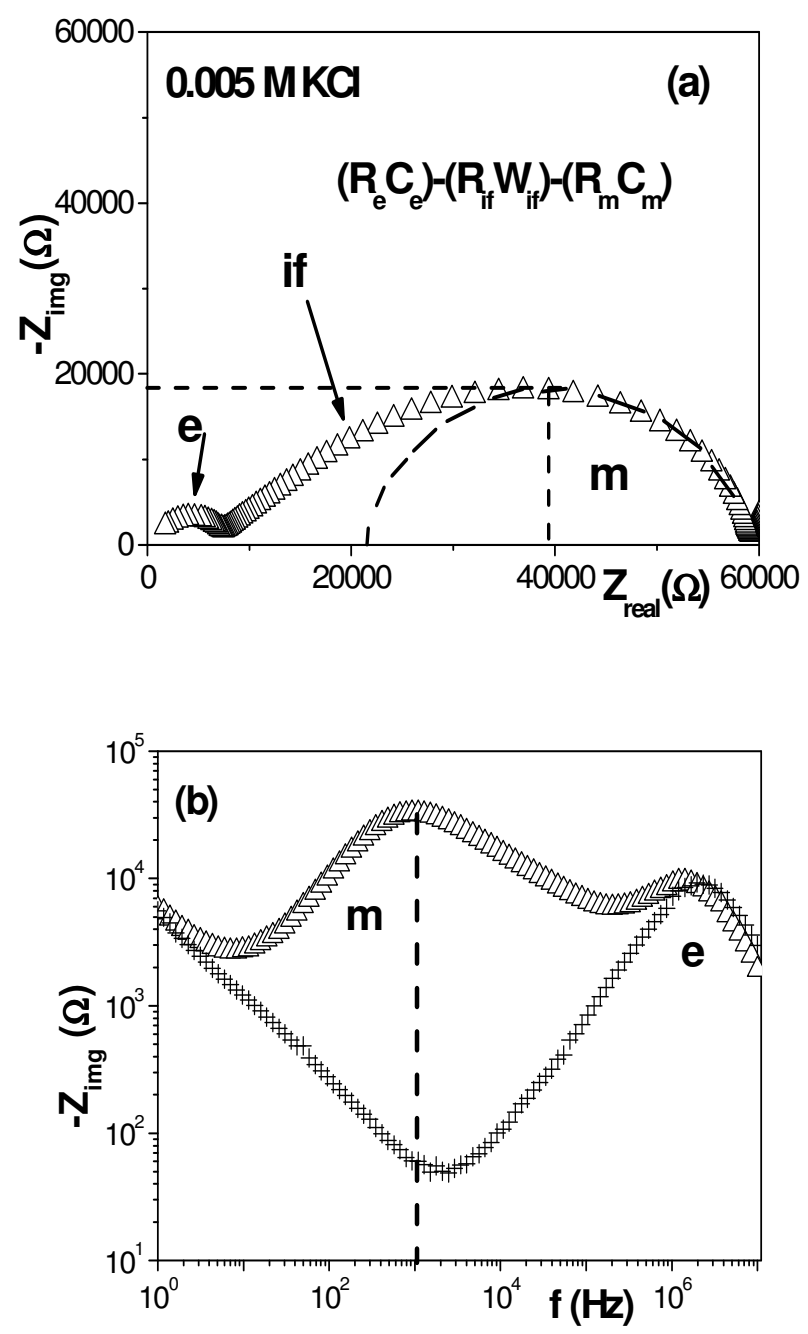

Figure 2. Impedance spectroscopy plots for a PET membrane in contact with a 0.005 $\mathrm{M} \mathrm{KCl}$ solution. (a) Nyquist plot; (b) Bode plot: $(\Delta)$ membrane/electrolyte system, $(+)$ electrolyte solution. 

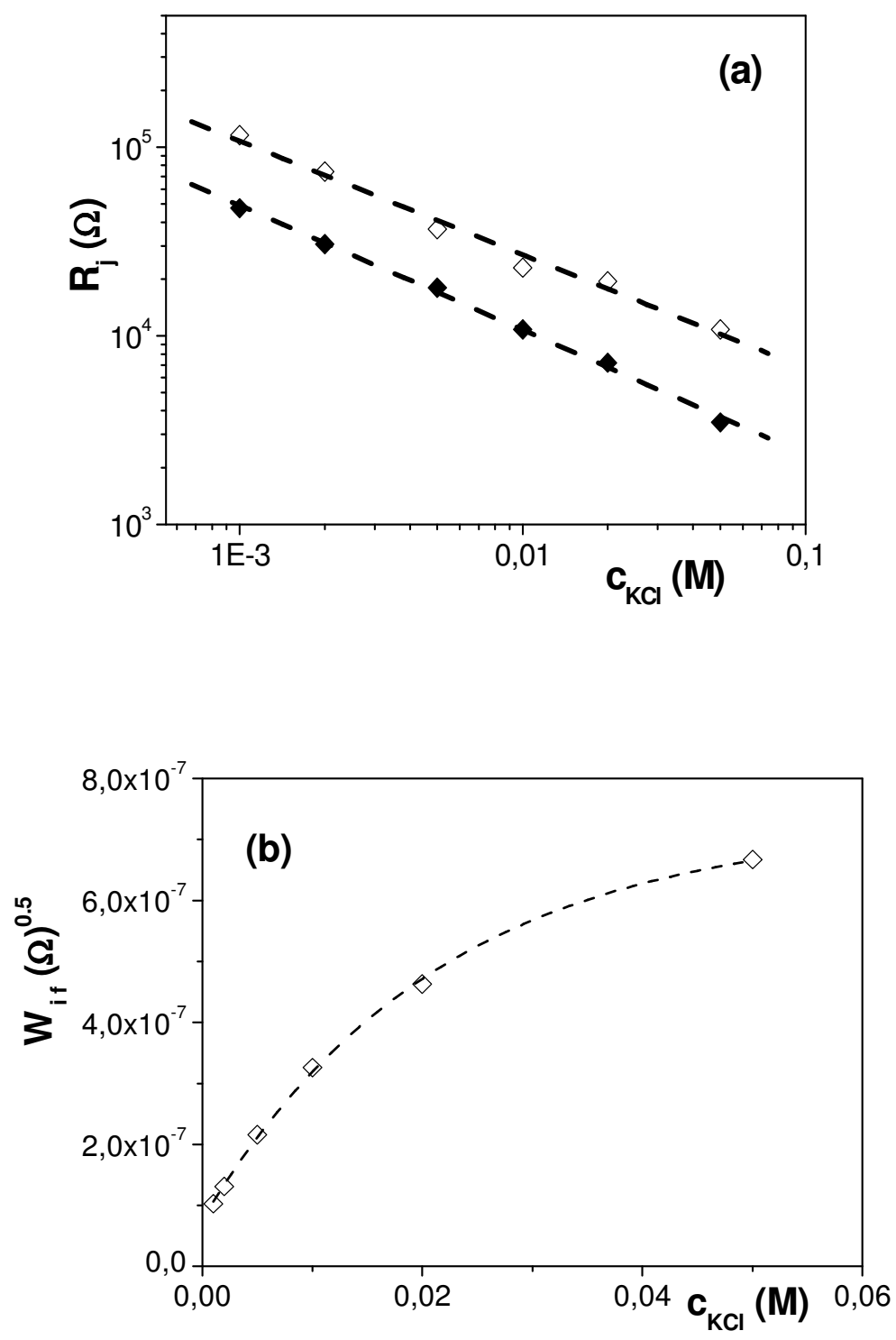

Figure 3. (a) Variation of PET membrane and interfacial electrical resistance $\left(R_{m}\right.$ and $\mathrm{R}_{\mathrm{if}}$, respectively) with $\mathrm{KCl}$ concentration. (b) variation of interfacial Warburg impedance with $\mathrm{KCl}$ concentration.

Impedance spectroscopy (IS) measurements permit us to get information on the electrical parameters associated to the membrane and/or the membrane/solution interface by analyzing the impedance plots and using equivalent circuits as models (17-19), which might be used to elucidate the main membrane fouling effect. IS is a useful tool for the study of heterogeneous systems consisting in a series array of layers with different electrical properties (such as electrolyte/membrane systems), since it allows the separate determination of the electrical parameters associated to each sublayer. The analysis of the impedance data was carried out by the complex plane $Z^{*}$ method by plotting the impedance imaginary part $\left(-Z_{i m g}\right)$ versus the real part $\left(Z_{\text {real }}\right)$. A single parallel R-C circuit 
gives rise to a semi-circle in the $Z^{*}$ plane, which has intercepts on the axis $Z_{\text {real }}$ at $R_{\infty}(\omega->\infty)$ and $R_{0}(\omega->0)$, the resistance of the system is given by $\left(R_{0}-R_{\infty}\right)$ (20); the maximum of the semi-circle equals $0.5\left(\mathrm{R}_{\mathrm{O}}-\mathrm{R}_{\infty}\right)$ and occurs at a frequency in which $\omega \mathrm{RC}=1$, being $\mathrm{RC}$ the relaxation time and $\omega$ the angular frequency $(\omega=2 \pi f)$. However, complex systems usually present a distribution of relaxation times and the resulting plot is a depressed semi-circle, which is represented by a non-ideal capacitor or constant phase element (CPE) (20), and its impedance is expressed by $\mathrm{Q}(\omega)=\mathrm{Y}_{\mathrm{O}}(\omega)^{-\mathrm{n}}$, where the admittance $\mathrm{Y}_{\mathrm{O}}\left(\Omega \mathrm{s}^{-\mathrm{n}}\right)$ and $n$ are two empirical parameters $(0 \leq n \leq 1)$; a particular case is obtained when $\mathrm{n}=0.5$, then the circuit element corresponds to a "Warburg Impedance" (W), which is associated to a diffusion process according to Fick's first law. Other typical impedance representation is the Bode plot (- $Z_{i m g}$ versus frequency), which allows the determination of the interval of frequency associated to a given relaxation process.

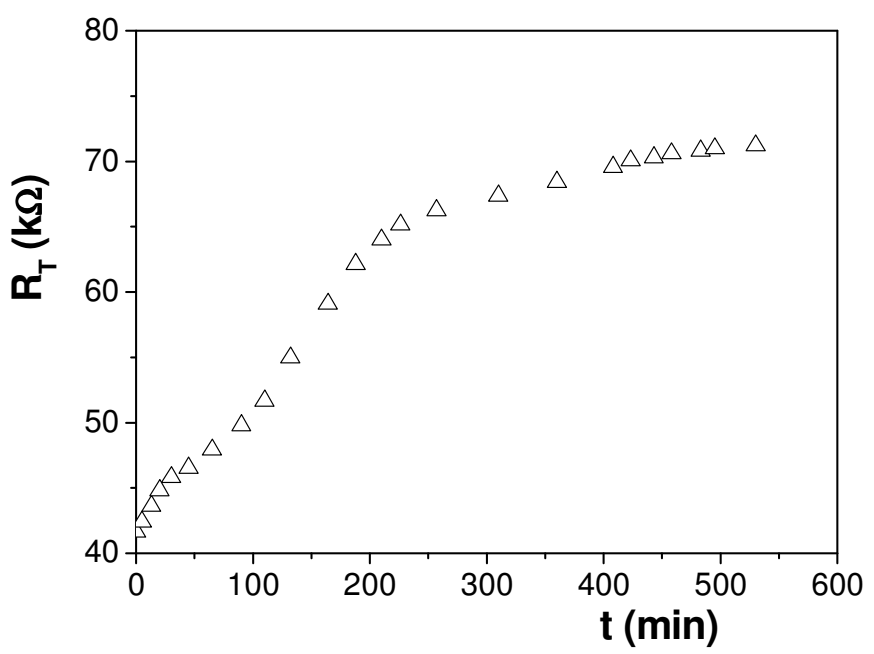

Figure 4. Time dependence of membrane system electrical resistance $\left(\mathrm{R}_{\mathrm{T}}\right)$ measured at a constant frequency $(1 \mathrm{kHz})$ for $\mathrm{c}_{\mathrm{KCl}}=0.01 \mathrm{M}$.

Fig. 2 shows the impedance plots and the equivalent circuit for the membrane in contact with a given $\mathrm{KCl}$ solution $(\mathrm{c}=0.005 \mathrm{M})$, where different and separate contributions can be observed: one corresponds to the electrolyte solution placed between the electrodes and the membrane and the other to the membrane contribution, where the asymmetry of the membrane electrical response can be observed in both pictures. For comparison, the electrical response associated to the electrolyte solution (measurement carried out without membrane in the cell) is also drawn in Fig. 2.b and very good agreement between these values and those assigned to the electrolyte contribution in the membrane/solution plot can be observed. The semi-circle obtained for the electrolyte contribution indicates that it consists in a parallel association of a resistance and a capacitance (cell capacitance) as was indicated above and it is represented by $\left(\mathrm{R}_{\mathrm{e}} \mathrm{C}_{\mathrm{e}}\right)$, while the 
asymmetry of the membrane electrical response indicates two different contributions, that is, two sub-circuits: i) the symmetric membrane itself, which is represented by the parallel association of the membrane electrical resistance and capacitance, $\left(\mathrm{R}_{\mathrm{m}} \mathrm{C}_{\mathrm{m}}\right)$; ii) the interfacial effects (if) associated to membrane fouling, which might cause a concentration profile in the solution near the membrane (diffusion), and it is represented by a Warburg impedance in parallel with a resistance $\left(\mathrm{R}_{\mathrm{if}} \mathrm{W}_{\mathrm{if}}\right)$. Similar curves were obtained for the other concentration studied.

The different electrical parameters were determined by fitting the experimental data to a non-linear program (21). Fig. 3.a shows the concentration dependence of both the membrane electrical resistance $\left(R_{m}\right)$ and the interfacial electrical resistance $\left(\mathrm{R}_{\mathrm{if}}\right)$, while the increase of the interfacial Warburg impedance with the increase of solution concentration is shown in Fig. 3.b; however, membrane capacitance is practically independent of salt concentration and the following average value for the total interval of concentration was obtained: $\langle\mathrm{C}\rangle=(2.7 \pm$ $0.2) \times 10-9 \mathrm{~F}$.

Table 1. Atomic concentrations percentages of the elements present in the surface of PET membranes maintained different time periods in water, determined from XPS analysis.

\begin{tabular}{|lccc|}
\hline Sample & C1s (\%) & O1s (\%) & N1s (\%) \\
\hline Membr. D(1) & 73.8 & 25.8 & 0.4 \\
\hline Memb. W1(2) & 73.1 & 25.5 & 1.4 \\
\hline Membr. W2(3) & 73.2 & 24.1 & 2.7 \\
\hline
\end{tabular}

(1) dry sample; (2) 1 week in water; (3) 1 month in water.

Fouling effect might be considered in order to explain both the nonreproducibility of the membrane potential values and the asymmetry of the impedance curves, which could mainly be associated to changes in the solution/membrane interface according to the IS results. This point was considered by measuring the temporal variation of the "membrane system" or total electrical resistance $\left(\mathrm{R}_{\mathrm{T}}=\mathrm{R}_{\mathrm{e}}+\mathrm{R}_{\mathrm{if}}+\mathrm{R}_{\mathrm{m}}\right)$ for a given solution $(0.01 \mathrm{M} \mathrm{KCl})$ by using an $\mathrm{AC}$ bridge at a fixed frequency ( $\mathrm{f}=1 \mathrm{kHz}$, which corresponds to the membrane electrical response according to Fig. 2.b). An increase of $\mathrm{R}_{\mathrm{T}}$ values as a function of time can be observed in Fig. 4, which is basically attributed to bacterial accumulation on the surface of this biodegradable material (although pore reduction could also exist) causing the increase of the electrical resistance. This point was checked by chemical surface analysis of the membrane surface for three different membrane samples: a dry PET membrane (D), a PET membrane maintained one week in distilled water (W1) and a PET membrane maintained 1 month in distilled water (W2), both at room temperature, and the obtained results are indicated in Table 1. As it was expected, carbon and oxygen are the PET membrane surface elements and the small percentage of nitrogen in 
the dry sample may be attributed to environmental contamination (11); however, for the samples maintained embedded in water the percentage of nitrogen is increasing with time, and bacterial contamination could be its origin. In any case, it should be pointed out that bacterial accumulation at the membrane surfaces may explain membrane asymmetry and the modification of the membrane/solution interface, but reduction of pore size or pore plugging could also be considered.

\section{Conclusions}

Modification of the membrane/solution interface associated to membrane fouling can affect different electrical parameters and this work shows the possible detection of this effect by measuring electrical resistance or membrane potential. Impedance spectroscopy was used to determine the electrical resistance of membranes in "working conditions" (in contact with electrolyte solutions) since it allows the separate determination of the membrane and the solution contributions as well as the interfacial characterization. Bacterial accumulation at the PET membrane surfaces was considered the origin of membrane fouling, which affects the membrane electrical parameters, and this assert was confirmed from XPS analysis of dry and wet PET membrane surfaces.

\section{Acknowledgements}

The authors want to thank to Dr. Alexander Nechaev (Laboratory of Nuclear Filters, Russian Academy of Science, Moscow) for kindly submitting the membrane sample and to Junta de Andalucía for partial financial support (Grupo PAI FQM-258).

\section{References}

1. M. Mulder, Basic Principles of Membrane Technology, Kluwer, Dordrecht, 1992.

2. V. Gekas, G. Trägardh, B. Hallström, Ultrafiltration Membrane Performance Fundamentals, KF-Sigma, Lund (Sweden), 1993.

3. G. Belford, R.H. Davis, A.L. Sydney, J. Membr. Sci. 96 (1994) 1-65.

4. Ch. Causserand, M. Nyström, P. Aimar, J. Membr. Sci. 88 (1994) 245252.

5. J. Benavente, G. Jonsson, Colloid \& Surfaces A 138 (1998) 255-252.

6. M. Pontié, L. Durand-Bourlier, D. Lemordant, J.M. Lainé, Sep. Purif. Technol. 14 (1998) 1-9.

7. R. Blank, K.-H. Muth, S. Proske-Gerhards, E. Staude, Colloids \& Surf. A 140 (1998).

8. $\quad$ R. Takagi, M. Nakagaki, J. Membr. Sci. 53 (1990) 19-28.

9. L. Palacio, P. Prádanos, A. Henández, M.J. Ariza, J. Benavente, M. Nyström, Appl. Phys. A 73 (2001) 555-560.

10. C. Torras, R. Garcia-Vall, J. Membr. Sci. 233 (2004) 119-127. 
11. J.T.F. Keurentjes, J.G. Harbrecht, D. Brikman, J.H. Hanemaaijer, M.A. Cohen and H. van't Riet, J. Membr. Sci. 47 (1989) 333-340.

12. D. Brigs, M.P. Seah, Practical Surface Analysis: Auger and X-ray Photoelectron Spectroscopy, John Whiley \& Sons, Chischester, England, 1995.

13. Multitechnique ESCA Software Reference Manual for the PC-ACCESS SoftwareVersion 6.0, Physics Electronics, Minneapolis, 1995.

14. K.H. Meyer, J.F. Siever, Helv. Chim. Acta 19 (1936) 649-662.

15. T. Teorell, Transport phenomena in membranes, Discuss. Faraday Soc. 21 (1956) 9-32.

16. N. Lakshminarayanaiah, Transport Phenomena in Membranes, Academic Press, New York, USA, 1969.

17. A. Asaka, J. Membr. Sci. 50 (1990) 71-81.

18. J. Benavente, J.R. Ramos-Barrado, A. Heredia, Colloids \& Surf. A 140 (1998) 333-338.

19. J. Benavente, J.M. García, J. de la Campa, J. de Abajo, J. Membr. Sci. 175 (2000), 43-50.

20. J.R. MacDonald, Impedance Spectroscopy, Wiley, New York, 1987.

21. B.A. Boukamp, Solid State Ionics 18\&19 (1986) 136. 